\title{
A COMPARISON BETWEEN CRASH AND CASUALTY ECONOMIC ANALYSIS APPROACHES OF ROAD SAFETY INFRASTRUCTURE COUNTERMEASURES
}

\author{
Chris Bic Byaruhanga', Harry Evdorides ${ }^{2}$ \\ 1,2 Department of Civil Engineering, University of Birmingham, Birmingham, UK
}

Received 19 October 2021; accepted 5 December 2021

\begin{abstract}
The economic analysis of safety measures is one of the core elements of a road safety program aimed at determining accurately the economic benefits. However, there is still a mix of approaches in some of the most widely used road safety investment appraisal models. For example, SafetyAnalyst is a crash-based evaluation model while the International Road Assessment Programme (iRAP) is a casualty-based model. The objective of this study was to compare crash with casualty based economic analysis approaches of infrastructure related safety countermeasures to inform economists and road safety analysts on the most appropriate approach. The study utilises data from 9 countries and the 20 -year infrastructure improvement program for Netherlands developed using EuroRAP and ViDA software. The results of this study demonstrated that a crash-based approach is more comprehensive and results in a wider range of countermeasures selected for implementation. In addition, compared to a casualty-based approach the value of safety benefits and the number of countermeasures selected increased by $26 \%$ and $10 \%$ respectively using a crash-based approach. This paper suggests that any road safety appraisal model may perform better by considering crashes instead of casualties and more so if the property damage only crashes are included in the analysis.
\end{abstract}

Keywords: road safety, economic analysis, infrastructure countermeasures, crash unit cost, casualty unit cost, model.

\section{Introduction}

The economic analysis of road safety countermeasures is one of the core elements of a road safety program aimed at determining accurately the economic benefits (Welle et al., 2018). However, as evidenced in the most widely used road safety investment appraisal models, SafetyAnalyst (Harwood et al., 2010) and Benefit Cost Analysis (BCA) by FHWA (2018) are crashbased models while the International Road
Assessment Programme (iRAP, 2015) is a casualty-based model. Moreover, Economic Efficiency Evaluation $\left(\mathrm{E}^{3}\right)$ model conducts economic analysis for both crashes and casualties (Martensen and Lassare, 2017); in this case, the choice depends on whether the countermeasure is to prevent crashes thus using a crash-based approach or mitigating the consequences of a crash such as seatbelts thus using a casualty-based approach. To this end, the focus of this paper is to examine the selection of infrastructure measures

${ }^{1}$ Corresponding author: cxb1018@student.bham.ac.uk 
to prevent crashes versus a casualty-based approach that may underestimate benefits within a comprehensive safe road system.

Harmon et al. (2018) recommends analysts to work with crashes and crash unit costs during economic appraisal of safety countermeasures. Similarly, in a report by OECD/ITF (2015), the efficiency assessment of a safety related measure requires the number of road crashes or accidents affected by a measure. In PIARC (2020), the key measure to assess effectiveness of any safety infrastructure intervention is the expected reduction in crashes expressed as a crash modification factor (CMF). However, Martensen et al. (2016) considers the effectiveness of a measure as a reduction in either the number of crashes or the number of casualties. Similarly, the most common ways of measuring progress in road safety is by the number of road crashes, the number of road casualties and the associated negative consequences (Wegman, 2017). In practice, crash and casualty-based approaches are used in economic analysis of road safety infrastructure measures most probably without due consideration of the impact of either approach on the calculated economic benefits and ultimately the selection of countermeasures. The economic implications might be substantial if for instance instead of analysing crashes, casualties are analysed and a significant proportion of crashes not involving casualties are not considered. For instance, in Germany and Finland, the property damage only (PDO) crashes have a share of up to $50 \%$ in total costs for road crashes. Furthermore, in the analysis conducted for countries that include all severity levels, PDO crashes accounted for $2 \%$ to $55 \%$ share in the total cost of crashes, which is higher than that of slight injuries ranging between $1.9 \%$ and $34 \%$ (Wijnen et al., 2017). Therefore, this study aims to clarify the economic benefits of these two approaches and their impact in the selection of infrastructure countermeasures.

\subsection{Economic Analysis of Road Safety Countermeasures}

Economic analysis is a process that allows organisations to identify, quantify and determine the value of economic costs and benefits of chosen countermeasures over the appraisal period to ensure efficiency and effectiveness of safety programs (U.S. DOT, 2003). Cost effectiveness, cost utility and cost benefit analyses tools identify how to use scarce resources to obtain the greatest possible benefit or the highest return on investments in road safety (Martensen et al., 2018).

The concept of economic analysis for safety measures is quite challenging due to the complex nature of determining the life cycle costs and benefits of countermeasures as well as crash or casualty unit costs. Consequently, this has led to arguments by Hauer (2011) describing the cost benefit analysis (CBA) tool as deficient due to uncertainties in defining the value of statistical life (VOSL) used. However, PIARC (2020) and Safety CaUsation, Benefits and Efficiency (SafetyCube) Decision Support System (Martensen et al., 2018) typically accept and use CBA as an economic evaluation tool. There is more substance to this tool subject to parameter estimation enhancement. For instance, this tool can underestimate safety benefits depending on the approach used; thus the need for sound economic analysis. The tool commonly used in road safety research determines the policy priorities and resource allocation typically through safety benefits expressed in terms of reduced number of crashes or casualties. 
A crash-based approach refers to an economic analysis in which the safety benefits of implementing a countermeasure are the number of crashes reduced. A road crash or accident refers to unplanned or uncontrolled event involving at least one vehicle, cyclist or motorcyclist and in which at least one person is killed, injured or property is damaged. Therefore, a crash can be fatal (at least one person is killed), serious (at least one person is seriously injured and no person killed), slight (at least one person is slightly injured but no person is killed or seriously injured) and finally a PDO crash in which no person is killed nor injured. In a casualty-based approach, the safety benefits of implementing a countermeasure are the number of casualties reduced. A casualty refers to a person killed or injured in a crash, subdivided into killed, seriously injured and slightly injured. In terms of severity levels, a crash-based approach has more severity levels than a casualty due to the property damage level added that might have a significant effect on the analysis results. In order to perform a CBA all relevant effects of the measure relating to safety, mobility (travel and vehicle expenses) and environment are paramount. However, the effects on mobility and environment appear complex to estimate and are scarce in the scholarly literature. Consequently, most of the appraisal models like SafetyAnalyst and iRAP ignore such effects in their economic analysis except the BCA model that estimates these effects based on reduced number of crashes. Therefore, in the advancement of economic analysis of safety measures, in order to utilise the available research with regard to mobility and environment, it is imperative that analysts develop or modify their models to analyse crash numbers instead of casualties.

\section{Methodology and Data}

To demonstrate the above approaches, the total cost of crashes and casualties was computed first using the number of crashes/ casualties (Table 1) for 9 European countries with the respective European Union (EU) standard crash and casualty unit costs for 2015 (Table 2 and Table 3) for each severity level and adding them together for each country.

Table 1

Crash and Casualty Data

\begin{tabular}{|l|c|c|c|c|c|c|c|}
\hline \multirow{2}{*}{ Country } & \multicolumn{4}{|c|}{ Crashes } & \multicolumn{3}{c|}{ Casualties } \\
\cline { 2 - 8 } & Fatal & $\begin{array}{c}\text { Serious } \\
\text { Injury }\end{array}$ & $\begin{array}{c}\text { Slight } \\
\text { Injury }\end{array}$ & PDO & Fatalities & $\begin{array}{c}\text { Serious } \\
\text { Injuries }\end{array}$ & $\begin{array}{c}\text { Slight } \\
\text { Injuries }\end{array}$ \\
\hline Austria & 429 & 9,262 & 26,917 & 646,553 & 523 & 10,502 & 34,522 \\
\hline Estonia & 61 & 433 & 1,345 & 29,218 & 67 & 467 & 1,756 \\
\hline Finland & 208 & 475 & 4,641 & 478,863 & 229 & 519 & 6,186 \\
\hline Germany & 3,187 & 58,744 & 240,504 & $2,104,250$ & 3,377 & 67,732 & 321,803 \\
\hline Iceland & 16 & 155 & 741 & 5,500 & 16 & 178 & 1,130 \\
\hline Ireland & 179 & 398 & 4,399 & 21,734 & 188 & 508 & 6,252 \\
\hline Norway & 148 & 597 & 4,380 & 403,719 & 160 & 693 & 5,670 \\
\hline Slovenia & 112 & 868 & 5,605 & 11,358 & 120 & 932 & 7,778 \\
\hline UK & 1,658 & 20,676 & 123,988 & $2,232,305$ & 1,775 & 22,807 & 169,895 \\
\hline
\end{tabular}

Source: (Wijnen et al., 2017) 
These unit costs developed by the European SafetyCube project aim to support stakeholders in conducting economic efficiency evaluation of measures. Secondly, the study computed a simple benefit cost ratio (BCR) to demonstrate the effect of these approaches on countermeasure selection considering only countermeasures with a BCR greater than 3. The monetary safety benefits are the number of crashes/casualties reduced multiplied with the respective unit costs (Table 2 and Table 3 ) and added together for all the severity levels. The 20-year infrastructure improvement program (Table A1) for Netherlands (Utrecht 2014 Provincial Roads) taken from iRAP (2021), developed using EuroRAP and ViDA software is used and modified accordingly to compute BCR.

Table 2

Crash Unit Cost and Components

\begin{tabular}{|c|c|c|c|c|c|c|c|}
\hline $\begin{array}{c}\text { Severity } \\
\text { Level }\end{array}$ & $\begin{array}{c}\text { Medical } \\
\text { Costs }\end{array}$ & $\begin{array}{c}\text { Production } \\
\text { Loss }\end{array}$ & $\begin{array}{c}\text { Human } \\
\text { Costs }\end{array}$ & $\begin{array}{c}\text { Property } \\
\text { Damage }\end{array}$ & $\begin{array}{c}\text { Administrative } \\
\text { Costs }\end{array}$ & $\begin{array}{c}\text { Other } \\
\text { Costs }\end{array}$ & $\begin{array}{c}\text { Total Unit } \\
\text { Costs (€) }\end{array}$ \\
\hline Fatal & 11,757 & 727,616 & $1,809,467$ & 17,542 & 8,891 & 3,817 & $2,579,090$ \\
\hline Serious Injury & 19,158 & 50,285 & 263,945 & 11,143 & 5,557 & 709 & 350,797 \\
\hline Slight injury & 1,957 & 3,629 & 21,212 & 7,231 & 2,677 & 634 & 37,340 \\
\hline PDO & 0 & 0 & 0 & 2795 & 764 & 400 & 3,959 \\
\hline
\end{tabular}

Source: (Wijnen et al., 2017)

\section{Table 3}

Casualty Unit Cost and Components

\begin{tabular}{|c|c|c|c|c|c|c|c|}
\hline $\begin{array}{c}\text { Severity } \\
\text { Level }\end{array}$ & $\begin{array}{c}\text { Medical } \\
\text { Costs }\end{array}$ & $\begin{array}{c}\text { Production } \\
\text { Loss }\end{array}$ & $\begin{array}{c}\text { Human } \\
\text { Costs }\end{array}$ & $\begin{array}{c}\text { Property } \\
\text { Damage }\end{array}$ & $\begin{array}{c}\text { Administrative } \\
\text { Costs }\end{array}$ & $\begin{array}{c}\text { Other } \\
\text { Costs }\end{array}$ & $\begin{array}{c}\text { Total Unit } \\
\text { Costs }(\boldsymbol{\epsilon})\end{array}$ \\
\hline Fatalities & 5,430 & 655,376 & $1,587,001$ & 11,555 & 6,346 & 3,638 & $2,269,346$ \\
\hline $\begin{array}{c}\text { Serious } \\
\text { Injuries }\end{array}$ & 16,719 & 43,627 & 230,385 & 7,622 & 4,364 & 413 & 303,130 \\
\hline Slight Injuries & 1,439 & 2,669 & 15,597 & 5,317 & 1,876 & 519 & 27,417 \\
\hline
\end{tabular}

Source: (Wijnen et al., 2017)

In iRAP, the number of casualties reduced due to countermeasure implementation depend on the risk factors that change the star rating score for the $100 \mathrm{~m}$ road segments. This data was the basis in estimating the number of fatalities and injuries and the number of crashes for all severity levels using the ratios (Table 4 and Table 5) developed from real crash and casualty data (Table 1).

Table 4

Relationship between Crash and Casualty Severity Levels

\begin{tabular}{|c|c|c|c|}
\hline \multirow{2}{*}{ Crash } & \multicolumn{3}{|c|}{ Casualties } \\
\cline { 2 - 4 } & Fatalities & Serious Injuries & Slight Injuries \\
\hline Fatal & 1.08 & - & - \\
\hline Serious Injury & - & 1.14 & - \\
\hline Slight Injury & - & - & 1.35 \\
\hline
\end{tabular}

Source: (Author's own computation) 
Table 5

Relationship between Casualty Severity Levels

\begin{tabular}{|c|c|c|}
\hline \multicolumn{3}{|c|}{ Casualties } \\
\hline Fatality & Serious Injuries & Slight Injuries \\
\hline 1 & 7 & 45 \\
\hline
\end{tabular}

Source: (Author's own computation)

The ratios in Table 4 are comparable to the number of casualties per crash by severity level in Greece and Norway (Wijnen et al., 2017) and those used in other countries and studies to estimate the number of crashes (De Brabander and Veereck, 2007; Wijnen, 2020). The total number of fatalities and serious injuries (FSI) as per iRAP was split considering 7 serious injuries per fatality (Table 5) which is slightly lower than the 10 serious injuries per fatality used in iRAP (iRAP, 2015). The PDO crashes are $88.7 \%$ of the total crashes using data in Table 1 and this determined the number of PDO crashes in the crash-based approach. Therefore, in this study for every injury, there are approximately $6 \mathrm{PDO}$ crashes, which is comparable to the recommended 6 PDO crashes in urban areas and 5.3 PDO crashes established in South Africa (Luathep and Tanaboriboon, 2005).

\section{Results and Discussion}

The study has compared crash and casualty economic analysis approaches and their impact on countermeasure selection during economic appraisal of safety related infrastructure countermeasures. It is limited to the crash and casualty data, crash-tocasualty ratios, crash/casualty unit costs and the cost of countermeasures presented. In addition, other principles involved in cost estimation such as discounting are not considered.

\subsection{Comparing the total cost of crashes and casualties}

Table A2 presents the cost of crashes and casualties computed using crash/casualty numbers with their respective unit costs. Considering all the severity levels in both cases, on average, the total cost of crashes is higher by over $70 \%$ compared to the total cost of casualties. In countries like Finland and Norway, the total cost of crashes is much higher since $99 \%$ of the total crashes are PDO crashes. On average, the PDO crashes are approximately $90 \%$ of the total number of crashes and these account for over $30 \%$ of the total cost of crashes which agrees with the previous findings by Wijnen et al. (2017) where in Germany and Finland the PDO crashes had a share of up to $50 \%$ of the total cost of road crashes. Similarly, in a study conducted in Singapore, the PDO crashes were $50 \%$ of the total cost of crashes (Chin, 2003). In addition, in Netherlands, about $24 \%$ of the total cost of crashes is attributable to PDO crashes (SWOV, 2020). This implies that PDO crashes generally have a significant impact on the total cost of crashes and thus on the results of an economic analysis of countermeasures. Therefore, in an economic appraisal of road safety countermeasures, considering the number of crashes prevented gives a more realistic representation of the actual benefits that might accrue with countermeasure implementation than the casualty approach. In addition, the safety 
benefits are higher in a crash-based approach as the crash unit cost is usually higher than a casualty unit cost since crashes include one or more vehicles and persons (Wijnen et al., 2017; De Brabander and Vereeck, 2007).

\subsection{The Impact of Crash and Casualty Approaches on Countermeasure Selection}

Table A3 presents the recomputed BCR values using the iRAP approach, which have changed significantly largely due to the unit costs and ratios used presented in Table 3 and Table 5 respectively that perhaps differ from those used to compute the BCR values in Table A1. The iRAP model performs economic analysis of single or multiple countermeasures during the preparation of the safer roads investment plans (iRAP, 2015). Although iRAP does not consider all the injury severity levels, it is typically a casualty-based model. In this approach, the number of fatalities and serious injuries saved are considered and this results into the selection of 26 countermeasures (Table A3).

Including the number of slight injuries saved in the casualty-based approach results in the selection of 30 countermeasures presented in Table A4. This represents an increase of $15 \%$ in the number of countermeasures selected compared to the iRAP approach. In addition, the value of safety benefits increases by $28 \%$ for each of the countermeasures in the casualty-based approach. For example, the safety benefits of implementing signalised crossings increase from $€ 5.5$ million in the iRAP approach to $€ 7.0$ million in the casualty-based approach.

Generally, the change in the number of countermeasures selected and safety benefits is significant because slight injuries on average are $85 \%$ of the total number of casualties and account for over $20 \%$ of the total cost of casualties (Table A2) which is between $1.9 \%$ and 34\% previously established by Wijnen at al. (2017). In Great Britain (DfT, 2020), the slight injuries were 79\% of the total number of casualties in 2019. This gives an implication, that even in a casualtybased model like iRAP, it is important to consider slight injuries during economic appraisal of countermeasures as they have a significant impact on countermeasure selection.

In the crash-based approach, there are 33 countermeasures selected for implementation as presented in Table A5. This accounts for a $10 \%$ increase in the number of countermeasures selected compared to the casualty-based approach shown in Table A4. In addition, the safety benefits increase by $26 \%$ for each of the countermeasures being analysed. For instance, the safety benefits of implementing signalised crossings increase from $€ 7.0$ million in casualty-based approach to $€ 8.8$ million in crash-based approach. Generally, the results show that a crashbased approach is more effective compared to a casualty-based approach as the BCR threshold values are increased. This explains why road safety economists should ideally work with crashes and not casualties as previously recommended by Harmon et al. (2018). The increase is justified partly by the large number of PDO crashes, which on average are $90 \%$ of the total crashes (c.f. Table A2) which is comparable to $88.3 \%$ established on the network of Korean expressways in 2008 by Park et al. (2012). Therefore, in a casualty-based approach, there is a likelihood of a good number of crashes not considered that may not result in any casualty as seen above. 
The difference in unit costs together with the number of PDO crashes have a much higher impact on the economic analysis results. This supports the previous argument by Wijnen et al. (2017) where the PDO crashes are major cost components in most countries and their exclusion might result in underestimation of total cost of crashes. This impact is cumulative with more severity levels considered and becomes substantial with the addition of PDO crashes, which are usually more than the other severity levels. The implementation of a particular measure may have differing effects depending on the severity level, which is important in any evaluation. It is important at this stage to remember that most infrastructure measures are designed based on an analysis of crash data and accident causation and not on casualties' causation thus leading to countermeasure effectiveness often expressed in terms of a crash reduction and not a casualty reduction, hence the common term CMF. In addition, to facilitate international comparison and standardise accident data collection, economic analysis of countermeasures must also be standardised and streamlined with regard to the crashbased approach.

The analysis above is a specific case study used as a demonstrator of the need to consider crash-based costs instead of casualty-based costs and without examining whether there are constraints in the road safety budget. In addition, the overall countermeasures prioritisation procedure requires examination with regard to the existing road conditions together with the selection and prioritisation mechanism. For example, it is important to group the countermeasures with regard to their frequency of implementation and the budget source. In other words, distinction is required of the above countermeasures as routine, periodic or rehabilitation works. This can have a significant impact on the final selection of countermeasures together with any budget constraints of the agency responsible for implementing the above countermeasures programme (Azmi and Evdorides, 2019).

\section{Conclusion}

Based on the above analysis, the following conclusions may be drawn:

1. The total cost of road crashes is higher than that of casualties;

2. A crash-based approach is superior to a casualty-based approach that underestimates safety benefits;

3. A crash-based approach results in a wider range of countermeasures selected for implementation due to enhanced economic justification;

4. A crash-based approach does not change the priority of the countermeasures;

5. A more comprehensive countermeasure selection and prioritisation process is required to take into account budget constraints, road safety implementation works, discounting and full life cycle analysis.

\section{Acknowledgements}

The authors acknowledge with gratitude the continuing support and finances in conducting this research provided by the Commonwealth Scholarship Commission (CSC) and University of Birmingham, UK. 


\section{Appendices}

\section{Table A1}

Infrastructure Improvement Program (Utrecht)

\begin{tabular}{|c|c|c|c|c|c|c|}
\hline $\mathrm{S} / \mathrm{N}$ & Countermeasure & \begin{tabular}{|l|} 
Length / \\
Sites
\end{tabular} & \begin{tabular}{|l} 
Fatalities \& \\
serious \\
injuries \\
saved
\end{tabular} & \begin{tabular}{|l|} 
Present \\
value of \\
safety \\
benefit $(€)$ \\
\end{tabular} & \begin{tabular}{|l|} 
Estimated \\
Cost $(€)$
\end{tabular} & $\begin{array}{l}\text { Program } \\
\text { BCR }\end{array}$ \\
\hline 1 & Signalised crossing & 1 sites & 10 & $3,233,649$ & 45,000 & 72 \\
\hline 2 & Improve curve delineation & $0.40 \mathrm{~km}$ & 0.5 & 148,419 & 7,460 & 20 \\
\hline 3 & Sight distance (obstruction removal) & $1.40 \mathrm{~km}$ & 2 & 678,298 & 35,280 & 19 \\
\hline 4 & Pedestrian fencing & $27.20 \mathrm{~km}$ & 9 & $2,976,955$ & 179,606 & 17 \\
\hline 5 & Street lighting (intersection) & 14 sites & 21 & $6,599,575$ & 504,000 & 13 \\
\hline 6 & Refuge Island & 14 sites & 14 & $4,606,949$ & 416,422 & 11 \\
\hline 7 & Shoulder rumble strips & $199.30 \mathrm{~km}$ & 84 & $27,156,276$ & $2,382,592$ & 11 \\
\hline 8 & Protected turn lane (unsignalised 4 leg) & 3 sites & 14 & $4,375,323$ & 535,399 & 8 \\
\hline 9 & Unsignalised crossing & 5 sites & 4 & $1,230,100$ & 217,465 & 6 \\
\hline 10 & Centreline rumble strip / flexi-post & $1.80 \mathrm{~km}$ & 0.3 & 108,423 & 19,512 & 6 \\
\hline 11 & Central hatching & $5.70 \mathrm{~km}$ & 0.6 & 184,481 & 34,173 & 5 \\
\hline 12 & Parking improvements & $1.50 \mathrm{~km}$ & 0.3 & 99,666 & 18,900 & 5 \\
\hline 13 & Improve Delineation & $45.70 \mathrm{~km}$ & 13 & $4,190,892$ & 847,446 & 5 \\
\hline 14 & Traffic calming & $2.90 \mathrm{~km}$ & 1 & 370,148 & 87,581 & 4 \\
\hline 15 & Central median barrier (no duplication) & $0.70 \mathrm{~km}$ & 1 & 365,701 & 95,182 & 4 \\
\hline 16 & Protected turn lane (unsignalised 3 leg) & 54 sites & 74 & $23,918,473$ & $7,210,571$ & 3 \\
\hline 17 & Footpath provision driver side (adjacent to road) & $27.90 \mathrm{~km}$ & 35 & $11,319,681$ & $4,388,280$ & 3 \\
\hline 18 & Footpath provision passenger side ( $>3 \mathrm{~m}$ from road) & $26.80 \mathrm{~km}$ & 29 & $9,267,974$ & $3,085,368$ & 3 \\
\hline 19 & Footpath provision driver side ( $>3 \mathrm{~m}$ from road) & $25.40 \mathrm{~km}$ & 28 & $9,060,036$ & $2,922,040$ & 3 \\
\hline 20 & Bicycle Lane (off-road) & $3.50 \mathrm{~km}$ & 3 & $1,122,681$ & 392,156 & 3 \\
\hline 21 & Footpath provision passenger side (informal path $>1 \mathrm{~m}$ ) & $5.80 \mathrm{~km}$ & 1 & 406,768 & 141,451 & 3 \\
\hline 22 & Footpath provision driver side (informal path $>1 \mathrm{~m}$ ) & $4.70 \mathrm{~km}$ & 1 & 307,139 & 114,747 & 3 \\
\hline 23 & Roadside barriers - driver side & $206.20 \mathrm{~km}$ & 199 & $64,041,774$ & $27,898,500$ & 2 \\
\hline 24 & Roadside barriers - passenger side & $159.20 \mathrm{~km}$ & 111 & $35,791,424$ & $21,558,000$ & 2 \\
\hline 25 & Footpath provision passenger side (adjacent to road) & $44.10 \mathrm{~km}$ & 52 & $16,843,531$ & $6,939,120$ & 2 \\
\hline 26 & Central median barrier $(1+1)$ & $34.80 \mathrm{~km}$ & 41 & $13,286,137$ & $6,288,200$ & 2 \\
\hline 27 & Wide centreline & $12.50 \mathrm{~km}$ & 0.6 & 181,898 & 75,710 & 2 \\
\hline 28 & Delineation and signing (intersection) & 8 sites & 0.5 & 149,378 & 88,582 & 2 \\
\hline 29 & Road surface rehabilitation & $0.80 \mathrm{~km}$ & 0.4 & 115,173 & 70,435 & 2 \\
\hline 30 & Clear roadside hazards - driver side & $0.10 \mathrm{~km}$ & 0.1 & 34,232 & 20,000 & 2 \\
\hline 31 & Additional lane $(2+1$ road with barrier $)$ & $15.10 \mathrm{~km}$ & 80 & $25,660,031$ & $20,655,000$ & 1 \\
\hline 32 & Shoulder sealing driver side $(>1 \mathrm{~m})$ & $103.50 \mathrm{~km}$ & 40 & $12,712,184$ & $9,156,140$ & 1 \\
\hline 33 & Shoulder sealing passenger side $(>1 \mathrm{~m})$ & $71.50 \mathrm{~km}$ & 29 & $9,428,574$ & $6,334,720$ & 1 \\
\hline 34 & Duplication with median barrier & $1.20 \mathrm{~km}$ & 26 & $8,323,159$ & $6,480,000$ & 1 \\
\hline 35 & Street lighting (mid-block) & $10.30 \mathrm{~km}$ & 4 & $1,352,702$ & $1,483,200$ & 1 \\
\hline 36 & Upgrade pedestrian facility quality & 43 sites & 3 & 826,756 & 767,405 & 1 \\
\hline 37 & Lane widening (up to $0.5 \mathrm{~m}$ ) & $1.00 \mathrm{~km}$ & 2 & 684,333 & 656,756 & 1 \\
\hline 38 & Overtaking lane & $0.30 \mathrm{~km}$ & 1 & 339,394 & 405,000 & 1 \\
\hline 39 & Shoulder sealing passenger side $(<1 \mathrm{~m})$ & $6.60 \mathrm{~km}$ & 0.9 & 292,349 & 294,490 & 1 \\
\hline 40 & Protected turn provision at existing signalised site (4-leg) & 1 sites & 0.6 & 204,497 & 237,955 & 1 \\
\hline 41 & Lane widening $(>0.5 \mathrm{~m})$ & $0.10 \mathrm{~km}$ & 0.6 & 186,272 & 152,529 & 1 \\
\hline 42 & Clear roadside hazards (bike lane) & $1.20 \mathrm{~km}$ & 0.5 & 160,633 & 216,000 & 1 \\
\hline 43 & Shoulder sealing driver side $(<1 \mathrm{~m})$ & $1.50 \mathrm{~km}$ & 0.2 & 68,926 & 66,640 & 1 \\
\hline 44 & Side road signalised pedestrian crossing & 1 sites & 0.1 & 28,480 & 45,000 & 1 \\
\hline 45 & Street lighting (ped crossing) & 2 sites & 0.1 & 26,839 & 36,000 & 1 \\
\hline
\end{tabular}

Source: (IRAP, 2021) 
Table A2

Comparing the Cost of Crashes and Casualties

\begin{tabular}{|c|c|c|c|c|c|c|c|c|c|c|}
\hline \multirow[t]{2}{*}{ Country } & \multicolumn{5}{|c|}{ Crashes } & \multicolumn{4}{|c|}{ Casualties } & \multirow{2}{*}{$\begin{array}{c}\text { Cost of } \\
\text { crashes/Cost of } \\
\text { casualties }\end{array}$} \\
\hline & Fatal & Serious & Slight & PDO & Total cost of crashes $(€)$ & Fatal & Serious & Slight & Total cost of casualties $(€)$ & \\
\hline Austria & 429 & 9,262 & 26,917 & 646,553 & $7,920,295,531$ & 523 & 10,502 & 34,522 & $5,316,828,892$ & 1.49 \\
\hline Estonia & 61 & 433 & 1,345 & 29,218 & $475,115,953$ & 67 & 467 & 1,756 & $341,752,144$ & 1.39 \\
\hline Finland & 208 & 475 & 4,641 & 478,863 & $2,772,192,852$ & 229 & 519 & 6,186 & $846,606,266$ & 3.27 \\
\hline Germany & 3,187 & 58,744 & 240,504 & $2,104,250$ & $46,137,923,908$ & 3,377 & 67,732 & 321,803 & $37,018,055,453$ & 1.25 \\
\hline Iceland & 16 & 155 & 741 & 5,500 & $145,082,415$ & 16 & 178 & 1,130 & $121,247,886$ & 1.20 \\
\hline Ireland & 179 & 398 & 4,399 & 21,734 & $851,577,882$ & 188 & 508 & 6,252 & $752,038,172$ & 1.13 \\
\hline Norway & 148 & 597 & 4,380 & 403,719 & $2,353,003,850$ & 160 & 693 & 5,670 & $728,618,840$ & 3.23 \\
\hline Slovenia & 112 & 868 & 5,605 & 11,358 & $847,606,898$ & 120 & 932 & 7,778 & $768,088,106$ & 1.10 \\
\hline UK & 1,658 & 20,676 & 123,988 & $2,232,305$ & $24,996,617,407$ & 1,775 & 22,807 & 169,895 & $15,599,586,275$ & 1.60 \\
\hline
\end{tabular}

Source: (Author's own computation)

\section{Table A3}

Countermeasures Selected using the iRAP Approach

\begin{tabular}{|c|c|c|c|c|c|c|c|}
\hline $\mathbf{S} / \mathbf{N}$ & Countermeasure & \begin{tabular}{|l|} 
Length / \\
Sites
\end{tabular} & Fatalities & \begin{tabular}{|l|}
$\begin{array}{l}\text { Serious } \\
\text { injuries }\end{array}$ \\
\end{tabular} & \begin{tabular}{|l}
$\begin{array}{l}\text { Safety } \\
\text { benefit }(€)\end{array}$ \\
\end{tabular} & \begin{tabular}{|l|} 
Estimated \\
Cost $(€)$
\end{tabular} & \begin{tabular}{|l|} 
Program \\
BCR
\end{tabular} \\
\hline 1 & Signalised crossing & 1 sites & 1.3 & 8.8 & $5,489,070$ & 45,000 & 122 \\
\hline 2 & Improve curve delineation & $0.40 \mathrm{~km}$ & 0.1 & 0.4 & 274,454 & 7,460 & 37 \\
\hline 3 & Sight distance (obstruction removal) & $1.40 \mathrm{~km}$ & 0.3 & 1.8 & $1,097,814$ & 35,280 & 31 \\
\hline 4 & Pedestrian fencing & $27.20 \mathrm{~km}$ & 1.1 & 7.9 & $4,940,163$ & 179,606 & 28 \\
\hline 5 & Street lighting (intersection) & 14 sites & 2.6 & 18.4 & $11,527,047$ & 504,000 & 23 \\
\hline 6 & Shoulder rumble strips & $199.30 \mathrm{~km}$ & 10.5 & 73.5 & $46,108,188$ & $2,382,592$ & 19 \\
\hline 7 & Refuge Island & 14 sites & 1.8 & 12.3 & $7,684,698$ & 416,422 & 18 \\
\hline 8 & Protected turn lane (unsignalised 4 leg) & 3 sites & 1.8 & 12.3 & $7,684,698$ & 535,399 & 14 \\
\hline 9 & Unsignalised crossing & 5 sites & 0.5 & 3.5 & $2,195,628$ & 217,465 & 10 \\
\hline 10 & Central hatching & $5.70 \mathrm{~km}$ & 0.1 & 0.5 & 329,344 & 34,173 & 10 \\
\hline 11 & Parking improvements & $1.50 \mathrm{~km}$ & 0.0 & 0.3 & 164,672 & 18,900 & 9 \\
\hline 12 & Centreline rumble strip / flexi-post & $1.80 \mathrm{~km}$ & 0.0 & 0.3 & 164,672 & 19,512 & 8 \\
\hline 13 & Improve Delineation & $45.70 \mathrm{~km}$ & 1.6 & 11.4 & $7,135,791$ & 847,446 & 8 \\
\hline 14 & Traffic calming & $2.90 \mathrm{~km}$ & 0.1 & 0.9 & 548,907 & 87,581 & 6 \\
\hline 15 & Central median barrier (no duplication) & $0.70 \mathrm{~km}$ & 0.1 & 0.9 & 548,907 & 95,182 & 6 \\
\hline 16 & Protected turn lane (unsignalised 3 leg) & 54 sites & 9.3 & 64.8 & $40,619,118$ & $7,210,571$ & 6 \\
\hline 17 & Footpath provision driver side ( $>3 \mathrm{~m}$ from road) & $25.40 \mathrm{~km}$ & 3.5 & 24.5 & $15,369,396$ & $2,922,040$ & 5 \\
\hline 18 & Footpath provision passenger side ( $>3 \mathrm{~m}$ from road) & $26.80 \mathrm{~km}$ & 3.6 & 25.4 & $15,918,303$ & $3,085,368$ & 5 \\
\hline 19 & Footpath provision driver side (informal path $>1 \mathrm{~m}$ ) & $4.70 \mathrm{~km}$ & 0.1 & 0.9 & 548,907 & 114,747 & 5 \\
\hline 20 & Footpath provision driver side (adjacent to road) & $27.90 \mathrm{~km}$ & 4.4 & 30.6 & $19,211,745$ & $4,388,280$ & 4 \\
\hline 21 & Wide centreline & $12.50 \mathrm{~km}$ & 0.1 & 0.5 & 329,344 & 75,710 & 4 \\
\hline 22 & Bicycle Lane (off-road) & $3.50 \mathrm{~km}$ & 0.4 & 2.6 & $1,646,721$ & 392,156 & 4 \\
\hline 23 & Footpath provision passenger side (adjacent to road) & $44.10 \mathrm{~km}$ & 6.5 & 45.5 & $28,543,164$ & $6,939,120$ & 4 \\
\hline 24 & Roadside barriers - driver side & $206.20 \mathrm{~km}$ & 24.9 & 174.1 & $109,232,493$ & $27,898,500$ & 4 \\
\hline 25 & Footpath provision passenger side (informal path $>1 \mathrm{~m}$ ) & $5.80 \mathrm{~km}$ & 0.1 & 0.9 & 548,907 & 141,451 & 4 \\
\hline 26 & Central median barrier $(1+1)$ & $34.80 \mathrm{~km}$ & 5.1 & 35.9 & $22,505,187$ & $6,288,200$ & 4 \\
\hline
\end{tabular}

Source: (Author's own computation) 


\section{Table A4}

Countermeasures Selected using the Casualty-based Approach (all Severity Levels)

\begin{tabular}{|c|c|c|c|c|c|c|c|c|}
\hline $\mathbf{S} / \mathbf{N}$ & Countermeasure & \begin{tabular}{|l|} 
Length / \\
Sites
\end{tabular} & Fatalities & $\begin{array}{l}\text { Serious } \\
\text { injuries }\end{array}$ & \begin{tabular}{|l|} 
Slight \\
injuries
\end{tabular} & \begin{tabular}{|l|} 
Safety \\
benefit $(€)$
\end{tabular} & $\begin{array}{l}\text { Estimated } \\
\text { Cost }(€)\end{array}$ & \begin{tabular}{|l|} 
Program \\
BCR
\end{tabular} \\
\hline 1 & Signalised crossing & 1 sites & 1.3 & 8.8 & 56.4 & $7,035,172$ & 45,000 & 156 \\
\hline 2 & Improve curve delineation & $0.40 \mathrm{~km}$ & 0.1 & 0.4 & 2.8 & 351,759 & 7,460 & 47 \\
\hline 3 & Sight distance (obstruction removal) & $1.40 \mathrm{~km}$ & 0.3 & 1.8 & 11.3 & $1,407,034$ & 35,280 & 40 \\
\hline 4 & Pedestrian fencing & $27.20 \mathrm{~km}$ & 1.1 & 7.9 & 50.8 & $6,331,655$ & 179,606 & 35 \\
\hline 5 & Street lighting (intersection) & 14 sites & 2.6 & 18.4 & 118.4 & $14,773,861$ & 504,000 & 29 \\
\hline 6 & Shoulder rumble strips & $199.30 \mathrm{~km}$ & 10.5 & 73.5 & 473.7 & $59,095,445$ & $2,382,592$ & 25 \\
\hline 7 & Refuge Island & 14 sites & 1.8 & 12.3 & 78.9 & $9,849,241$ & 416,422 & 24 \\
\hline 8 & Protected turn lane (unsignalised 4 leg) & 3 sites & 1.8 & 12.3 & 78.9 & $9,849,241$ & 535,399 & 18 \\
\hline 9 & Unsignalised crossing & 5 sites & 0.5 & 3.5 & 22.6 & $2,814,069$ & 217,465 & 13 \\
\hline 10 & Central hatching & $5.70 \mathrm{~km}$ & 0.1 & 0.5 & 3.4 & 422,110 & 34,173 & 12 \\
\hline 11 & Parking improvements & $1.50 \mathrm{~km}$ & 0.0 & 0.3 & 1.7 & 211,055 & 18,900 & 11 \\
\hline 12 & Centreline rumble strip / flexi-post & $1.80 \mathrm{~km}$ & 0.0 & 0.3 & 1.7 & 211,055 & 19,512 & 11 \\
\hline 13 & Improve Delineation & $45.70 \mathrm{~km}$ & 1.6 & 11.4 & 73.3 & $9,145,724$ & 847,446 & 11 \\
\hline 14 & Traffic calming & $2.90 \mathrm{~km}$ & 0.1 & 0.9 & 5.6 & 703,517 & 87,581 & 8 \\
\hline 15 & Central median barrier (no duplication) & $0.70 \mathrm{~km}$ & 0.1 & 0.9 & 5.6 & 703,517 & 95,182 & 7 \\
\hline 16 & Protected turn lane (unsignalised 3 leg) & 54 sites & 9.3 & 64.8 & 417.3 & $52,060,273$ & $7,210,571$ & 7 \\
\hline 17 & Footpath provision driver side (>3m from road) & $25.40 \mathrm{~km}$ & 3.5 & 24.5 & 157.9 & $19,698,482$ & $2,922,040$ & 7 \\
\hline 18 & Footpath provision passenger side (>3m from road) & $26.80 \mathrm{~km}$ & 3.6 & 25.4 & 163.5 & $20,401,999$ & $3,085,368$ & 7 \\
\hline 19 & Footpath provision driver side (informal path >1m) & $4.70 \mathrm{~km}$ & 0.1 & 0.9 & 5.6 & 703,517 & 114,747 & 6 \\
\hline 20 & Footpath provision driver side (adjacent to road) & $27.90 \mathrm{~km}$ & 4.4 & 30.6 & 197.4 & $24,623,102$ & $4,388,280$ & 6 \\
\hline 21 & Wide centreline & $12.50 \mathrm{~km}$ & 0.1 & 0.5 & 3.4 & 422,110 & 75,710 & 6 \\
\hline 22 & Bicycle Lane (off-road) & $3.50 \mathrm{~km}$ & 0.4 & 2.6 & 16.9 & $2,110,552$ & 392,156 & 5 \\
\hline 23 & Footpath provision passenger side (adjacent to road) & $44.10 \mathrm{~km}$ & 6.5 & 45.5 & 293.2 & $36,582,894$ & $6,939,120$ & 5 \\
\hline 24 & Roadside barriers - driver side & $206.20 \mathrm{~km}$ & 24.9 & 174.1 & 1122.2 & $139,999,922$ & $27,898,500$ & 5 \\
\hline 25 & Footpath provision passenger side (informal path $>1 \mathrm{~m}$ ) & $5.80 \mathrm{~km}$ & 0.1 & 0.9 & 5.6 & 703,517 & 141,451 & 5 \\
\hline 26 & Central median barrier $(1+1)$ & $34.80 \mathrm{~km}$ & 5.1 & 35.9 & 231.2 & $28,844,205$ & $6,288,200$ & 5 \\
\hline 27 & Road surface rehabilitation & $0.80 \mathrm{~km}$ & 0.1 & 0.4 & 2.3 & 281,407 & 70,435 & 4 \\
\hline 28 & Delineation and signing (intersection) & 8 sites & 0.1 & 0.4 & 2.8 & 351,759 & 88,582 & 4 \\
\hline 29 & Roadside barriers - passenger side & $159.20 \mathrm{~km}$ & 13.9 & 97.1 & 626.0 & $78,090,409$ & $21,558,000$ & 4 \\
\hline 30 & Clear roadside hazards - driver side & $0.10 \mathrm{~km}$ & 0.0 & 0.1 & 0.6 & 70,352 & 20,000 & 4 \\
\hline
\end{tabular}

Source: (Author's own computation)

\section{References}

Azmi, A.E.; Evdorides, H. 2019. Life-cycle rating of road maintenance works. In Nikolaides AF and Manthos E. Bituminous Mixtures and Pavements VII: Proceedings of the $7^{\text {th }}$ International Conference 'Bituminous Mixtures and Pavements' (7ICONFBMP). June 12-14, 2019, Thessaloniki, Greece. CRC Press, London, UK, 674 p.

Chin, H.C. 2003. The cost of traffic accidents in Singapore. In Proceedings of the Urban Transport IX. Ninth International Conference on Urban Transport and the Environment in the 21st Century. WIT Press, Southampton, UK, 514-524.
De Brabander, B.; Vereeck, L. 2007. Valuing the prevention of Road Accidents in Belgium, Transport Reviews 27(6): 715-732. doi: 10.1080/ 01441640701275362.

DfT (Department for Transport). 2020. Reported road casualties in Great Britain: 2019 annual report. DfT, UK. Available from Internet: <https://www.gov.uk/ government/statistics/reported-road-casualties-greatbritain-annual-report-2019> [accessed 2021 Feb 02].

FHWA (Federal Highway Administration). 2018. Highway Safety Benefit -Cost Analysis Tool: Reference Guide. FHWA, Office of Safety, Washington, DC, 


\section{Table A5}

Countermeasures Selected using the Crash-based Approach

\begin{tabular}{|c|c|c|c|c|c|c|c|c|c|}
\hline $\mathbf{S} / \mathbf{N}$ & Countermeasure & $\begin{array}{l}\text { Length / } \\
\text { Sites }\end{array}$ & Fatal & \begin{tabular}{|l}
$\begin{array}{l}\text { Serious } \\
\text { injury }\end{array}$ \\
\end{tabular} & \begin{tabular}{|l} 
Slight \\
injury
\end{tabular} & PDO & \begin{tabular}{|l} 
Safety \\
benefit $(€)$
\end{tabular} & \begin{tabular}{|l|} 
Estimated \\
Cost $(€)$ \\
\end{tabular} & \begin{tabular}{|l}
$\begin{array}{l}\text { Program } \\
\text { BCR }\end{array}$ \\
\end{tabular} \\
\hline 1 & Signalised crossing & 1 sites & 1.2 & 7.7 & 41.9 & 397.5 & $8,829,598$ & 45,000 & 196 \\
\hline 2 & Improve curve delineation & $0.40 \mathrm{~km}$ & 0.1 & 0.4 & 2.1 & 19.9 & 441,480 & 7,460 & 59 \\
\hline 3 & Sight distance (obstruction removal) & $1.40 \mathrm{~km}$ & 0.2 & 1.5 & 8.4 & 79.5 & $1,765,920$ & 35,280 & 50 \\
\hline 4 & Pedestrian fencing & $27.20 \mathrm{~km}$ & 1.0 & 6.9 & 37.7 & 357.8 & $7,946,638$ & 179,606 & 44 \\
\hline 5 & Street lighting (intersection) & 14 sites & 2.4 & 16.1 & 88.0 & 834.8 & $18,542,156$ & 504,000 & 37 \\
\hline 6 & Shoulder rumble strips & $199.30 \mathrm{~km}$ & 9.8 & 64.5 & 352.1 & 3339.4 & $74,168,624$ & $2,382,592$ & 31 \\
\hline 7 & $\begin{array}{l}\text { Refuge Island } \\
\end{array}$ & 14 sites & 1.6 & 10.8 & 58.7 & 556.6 & $12,361,437$ & 416,422 & 30 \\
\hline 8 & Protected turn lane (unsignalised $4 \mathrm{leg}$ ) & 3 sites & 1.6 & 10.8 & 58.7 & 556.6 & $12,361,437$ & 535,399 & 23 \\
\hline 9 & Unsignalised crossing & 5 sites & 0.5 & 3.1 & 16.8 & 159.0 & $3,531,839$ & 217,465 & 16 \\
\hline 10 & Central hatching & $5.70 \mathrm{~km}$ & 0.1 & 0.5 & 2.5 & 23.9 & 529,776 & 34,173 & 16 \\
\hline 11 & \begin{tabular}{|l|l}
1 & Parking improvements \\
\end{tabular} & $1.50 \mathrm{~km}$ & 0.0 & 0.2 & 1.3 & 11.9 & 264,888 & 18,900 & 14 \\
\hline 12 & Centreline rumble strip / flexi-post & $1.80 \mathrm{~km}$ & 0.0 & 0.2 & 1.3 & 11.9 & 264,888 & 19,512 & 14 \\
\hline 13 & Improve Delineation & $45.70 \mathrm{~km}$ & 1.5 & 10.0 & 54.5 & 516.8 & $11,478,478$ & 847,446 & 14 \\
\hline 14 & Traffic calming & $2.90 \mathrm{~km}$ & 0.1 & 0.8 & 4.2 & 39.8 & 882,960 & 87,581 & 10 \\
\hline 15 & Central median barrier (no duplication) & $0.70 \mathrm{~km}$ & 0.1 & 0.8 & 4.2 & 39.8 & 882,960 & 95,182 & 9 \\
\hline 16 & Protected turn lane (unsignalised 3 leg) & 54 sites & 8.6 & 56.9 & 310.2 & 2941.8 & $65,339,026$ & $7,210,571$ & 9 \\
\hline 17 & Footpath provision driver side (>3m from road) & $25.40 \mathrm{~km}$ & 3.3 & 21.5 & 117.4 & 1113.1 & $24,722,875$ & $2,922,040$ & 8 \\
\hline 18 & Footpath provision passenger side ( $>3 \mathrm{~m}$ from road) & $26.80 \mathrm{~km}$ & 3.4 & 22.3 & 121.6 & 1152.9 & $25,605,835$ & $3,085,368$ & 8 \\
\hline 19 & Footpath provision driver side (informal path >1m) & $4.70 \mathrm{~km}$ & 0.1 & 0.8 & 4.2 & 39.8 & 882,960 & 114,747 & 8 \\
\hline 20 & Footpath provision driver side (adjacent to road) & $27.90 \mathrm{~km}$ & 4.1 & 26.9 & 146.7 & 1391.4 & $30,903,593$ & $4,388,280$ & 7 \\
\hline 21 & Wide centreline & $12.50 \mathrm{~km}$ & 0.1 & 0.5 & 2.5 & 23.9 & 529,776 & 75,710 & 7 \\
\hline 22 & Bicycle Lane (off-road) & $3.50 \mathrm{~km}$ & 0.3 & 2.3 & 12.6 & 119.3 & $2,648,879$ & 392,156 & 7 \\
\hline 23 & Footpath provision passenger side (adjacent to road) & $44.10 \mathrm{~km}$ & 6.0 & 39.9 & 218.0 & 2067.2 & $45,913,910$ & $6,939,120$ & 7 \\
\hline 24 & Roadside barriers - driver side & $206.20 \mathrm{~km}$ & 23.1 & 152.9 & 834.1 & 7911.1 & $175,709,003$ & $27,898,500$ & 6 \\
\hline 25 & Footpath provision passenger side (informal path $>1 \mathrm{~m}$ ) & $5.80 \mathrm{~km}$ & 0.1 & 0.8 & 4.2 & 39.8 & 882,960 & 141,451 & 6 \\
\hline 26 & Central median barrier $(1+1)$ & $34.80 \mathrm{~km}$ & 4.8 & 31.5 & 171.9 & 1629.9 & $36,201,352$ & $6,288,200$ & 6 \\
\hline 27 & Road surface rehabilitation & $0.80 \mathrm{~km}$ & 0.0 & 0.3 & 1.7 & 15.9 & 353,184 & 70,435 & 5 \\
\hline 28 & Delineation and signing (intersection) & 8 sites & 0.1 & 0.4 & 2.1 & 19.9 & 441,480 & 88,582 & 5 \\
\hline 29 & Roadside barriers - passenger side & $159.20 \mathrm{~km}$ & 12.9 & 85.3 & 465.3 & 4412.7 & $98,008,539$ & $21,558,000$ & 5 \\
\hline 30 & Clear roadside hazards - driver side & $0.10 \mathrm{~km}$ & 0.0 & 0.1 & 0.4 & 4.0 & 88,296 & 20,000 & 4 \\
\hline 31 & Shoulder sealing passenger side $(>1 \mathrm{~m})$ & $71.50 \mathrm{~km}$ & 3.4 & 22.3 & 121.6 & 1152.9 & $25,605,835$ & $6,334,720$ & 4 \\
\hline 32 & Shoulder sealing driver side $(>1 \mathrm{~m})$ & $103.50 \mathrm{~km}$ & 4.6 & 30.7 & 167.7 & 1590.2 & $35,318,393$ & $9,156,140$ & 4 \\
\hline 33 & Duplication with median barrier & $1.20 \mathrm{~km}$ & 3.0 & 20.0 & 109.0 & 1033.6 & $22,956,955$ & $6,480,000$ & 4 \\
\hline
\end{tabular}

Source: (Author's own computation)

FHWA-SA-18-027. Available from Internet: <https:// safety.fhwa.dot.gov/hsip/docs/fhwasa18027.pdf $>$ [accessed 2019 Dec 02].

Harmon, T.; Bahar, G.; Gross, F. 2018. Crash Costs for Highway Safety Analysis. Federal Highway Administration, Office of Safety, Washington, DC, FHWA-SA-17-071. Available from Internet: <https:// safety.fhwa.dot.gov/hsip/docs/fhwasa 17071.pdf $>$ [accessed 2019 Dec 05].

Harwood, D.W.; Torbic, D.J.; Richard, K.R.; Meyer, M.M. 2010. SafetyAnalyst: Software Tools for Safety Management of Specific Highway Sites. Federal Highway Administration, USA, FHWA-RT-10-063.
Hauer, E. 2011. Computing what the public wants: Some issues in road safety cost-benefit analysis, Accident Analysis and Prevention 43:151-164.

iRAP (International Road Assessment Programme). 2015. iRAP Methodology Fact Sheet 13 Economic Analysis. iRAP, London, UK. Available from Internet: <https://www.irap.org/resources/?et_open_tab=et_ pb_tab_1\#mytabs $\mid 1>$ [accessed 2019 Dec 03].

iRAP (International Road Assessment Programme). 2021. iRAP Safer Roads Investment Plan. iRAP, London, UK. Available from Internet: <https://vida. irap.org/en-gb/dashboard $>$ [accessed 2021 Jan 02]. 
Luathep, P.; Tanaboriboon, Y. 2005. Determination of economic losses due to road crashes in Thailand, Journal of the Eastern Asia Society for Transportation Studies $6: 3413-3425$.

Martensen, H. et al. 2016. Preliminary guidelines for priority setting between measures. Deliverable Number 3.4 of the H2020 project SafetyCube. BRSI, Brussels.

Martensen, H.; Lassarre, S. Eds. 2017. Methodological framework for the evaluation of road safety risk factors and countermeasures. Deliverable 3.3 of the $\mathrm{H} 2020$ project SafetyCube. VIAS Institute, Belgium.

Martensen, H.; Daniels, S.; Van den Berghe, W. et al. 2018. Guidelines for priority setting between measures with practical examples. Deliverable Number 3.5 of the $\mathrm{H} 2020$ project SafetyCube. VIAS Institute, Belgium.

OECD/ITF (Organisation for Economic Cooperation and Development/International Transport Forum). 2015. Road infrastructure safety management. OECD/ITF, Paris, France. Available from Internet: <https://www.itf-oecd.org/sites/default/files/ docs/15irtadsafetymanagement.pdf $>$ [accessed 2020 Dec 02].

Park, S.; Jang, K.; Park, S.H.; Kim, D.K.; Chon, K.S. 2012. Analysis of injury severity in traffic crashes: A case study of Korean Expressways, KSCE Journal of Civil Engineering 16(7):1280-1288.

PIARC (Permanent Association of Road Congresses). 2020. Road Safety Manual: A manual for Practitioners and Decision makers on implementing safe system infrastructure. Available from Internet: <https:// roadsafety.piarc.org/en $>$ [accessed 2020 Aug 05].
SWOV (Institute for Road Safety Research). 2020. Road Crash Costs. SWOV Fact Sheet, SWOV, The Hague.

U.S. DOT (US Department of Transportation). 2003. Economic Analysis Primer, Federal Highway Administration, Washington, DC, FHWA-IF-03-032. Available from Internet: <https://www.webpages. uidaho.edu/ mlowry/Teaching/EngineeringEconomy/ Supplemental/USDOT_Economic_Analysis_Primer. pdf $>$ [accessed 2020 Aug 05].

Wegman, B. 2017. The future of road safety: A worldwide perspective, IATSS Research 40(2): 66-71.

Welle, B.; Sharpin, B.A.; Adriazola-Steil, C. et al. 2018. Sustainable \& Safe: A vision and Guidance for Zero Road Deaths. Washington, DC: World Resources Institute. $76 \mathrm{p}$.

Wijnen, W.; Weijermars, W.; Vanden Berghe, W. et al. 2017. Crash cost estimates for European countries. Deliverable 3.2 of the $\mathrm{H} 2020$ project SafetyCube. BRSI, Belgium.

Wijnen, W. 2020. Socio-economic costs of road crashes in middle-income countries: Applying a hybrid approach to Kazakhstan, IATSS Research 45(3): 293-302.

\section{jitte 60}

